\title{
A novel experimental set-up for simultaneous adsorption and induced deformation measurements in microporous materials
}

\author{
L. Perrier, ${ }^{1}$ F. Plantier, ${ }^{1}$ and D. Grégoire ${ }^{1, \text { a) }}$ \\ Laboratoire des Fluides Complexes et leurs Réservoirs \\ LFC-R, UM5150, Univ Pau \& Pays Adour, \\ Campus Montaury, 64600 Anglet, France
}

(Dated: 31 October 2017)

\begin{abstract}
A new experimental set-up is presented allowing the simultaneous measurement of adsorption isotherms and adsorption-induced deformations. It is composed of a manometric technique coupled with a digital image correlation set-up for full-field displacement measurements. The manometric part is validated by comparing adsorption isotherms with those obtained by a gravimetric method. The principles and methods of both adsorption isotherm and induced deformation measurements are presented in details. As a first application of this new apparatus, the coupling between adsorption and induced deformation is characterised for a microporous media (activated carbon) saturated by pure $\mathrm{CO}_{2}\left(318.15 \mathrm{~K},[0-60]\right.$ bar) and pure $\mathrm{CH}_{4}$ $(303.15 K,[0-130]$ bar $)$. For this very homogeneous porous material, the induced deformation is characteristic of a pure volumetric swelling but the full-field set up may allow the characterisation of localised pattern of deformation for heterogenous or cracked microporous media.
\end{abstract}

PACS numbers: 68.43.-hbra

Keywords: Adsorption; deformation; microporous materials; experiment; manometric technique; digital image correlation

\section{INTRODUCTION}

Following the IUPAC recommendation ${ }^{1,2}$, the pore space in porous materials is divided into three groups according to the pore size diameters: macropores of widths greater than $50 \mathrm{~nm}$, mesopores of widths between 2 and $50 \mathrm{~nm}$ and micropores (or nanopores) of widths less than $2 \mathrm{~nm}$. Zeolites, activated carbon, tight rocks, coal rocks, source rocks, cement paste or construction materials are among these materials. In recent years, a major attention has been paid on these microporous materials because the surface-to-volume ratio (i.e., the specific pore surface) increases with decreasing characteristic pore size. Consequently, these materials can trap an important quantity of fluid molecules as an adsorbed phase. This is important for applications in petroleum and oil recovery, gas storage, separation, catalysis or drug delivery.

For these microporous materials, a deviation from standard poromechanics, which was introduced by Biot 75 years ago $^{3,4}$, is expected. In very small pores, the molecules of fluid are confined. Interaction between molecules is modified. This effect, denoted as molecular packing, includes fluid-fluid and fluid-solid interactions and has significant consequences at the macroscale, such as instantaneous swelling deformation. In different contexts, these deformations may be critical. For instance, in situ adsorption-induced coal swelling has been identified $^{5,6}$ as the principal factor leading to a rapid decrease in $\mathrm{CO}_{2}$ injectivity during coal bed methane production enhanced by $\mathrm{CO}_{2}$ injection. Generally, natural

\footnotetext{
${ }^{a)}$ Corresponding author: david.gregoire@univ-pau.fr
}

and synthesised porous media are composed of a double porosity: the microporosity where the fluid is trapped as an adsorbed phase and a meso or a macro porosity required to ensure the transport of fluids to and from the smaller pores. If adsorption in nanopores induces instantaneous deformations at a higher scale, the matrix swelling may close the transport porosity, reducing the global permeability of the porous system or annihilating the functionality of synthesised materials. Conversely, gas desorption can lead to matrix shrinkage and microcracking, which may help oil and gas recovery in the context of unconventional petroleum engineering ${ }^{7}$. The effects of adsorbent deformation on physical adsorption has also been identified ${ }^{8}$ as the major challenge concerning gas porosimetry in nano-porous non-rigid materials (e.g. metal organic framework). In conclusion, there is now a consensus in the community that major attention has to be focused on the coupled effects appearing at the nanoscale within microporous media because they may have significant consequences at the macroscale.

Experimentally, different authors tried to combine gas adsorption results and volumetric swelling data. Pioneer works of Meehan ${ }^{9}$ showed the effect of carbon dioxyde sorption on the expansion of charcoal but only mechanical deformations were reported and no adsorption quantities were measured. Later on, different authors ${ }^{7,10-15}$ performed tests on bituminous coal, because it is of utmost importance in the context of $\mathrm{CO}_{2}$ geological sequestration and coal bed reservoirs exploitation. However, most results in the literature are not complete in a sense that adsorption and swelling experiments are not measured simultaneously ${ }^{9,16}$ or performed on the exact same coal samples ${ }^{12}$. Other authors presented simultaneous in situ adsorption and swelling results but the volumetric 
strain is extrapolated from a local measurement - using strain gauges ${ }^{7,17,18}$ or LVDT sensors ${ }^{15,19}$ - or by monitoring the silhouette expansion ${ }^{11}$.

Recently, important efforts have been involved in molecular simulations ${ }^{20-23}$ or in poromechanical modeling ${ }^{24-26}$ in order to predict adsorption-induced deformation in nanoporous materials. However, there is still a need for detailed experimental data presenting simultaneous adsorption-induced deformation measurements for validation purpose, especially for heterogeneous materials.

In this context, this paper aims to present a novel apparatus allowing the simultaneous in situ measurement of both the adsorption quantities and the deformations induced on the same sample. This apparatus is composed of a manometric technique coupled with a digital image correlation set-up for full-field displacement measurements. In section II, the novel apparatus is described and the experimental method is fully detailed by presenting both the manometric technique and the digital image correlation set-up. In section III, this new apparatus is used to characterise in situ adsorption-induced deformation on a nanoporous activated carbon saturated with pure methane and carbon dioxyde.

\section{EXPERIMENTAL APPARATUS : PRINCIPLES AND METHODS}

\section{A. Device description}

A new experimental set-up is proposed to measure insitu and simultaneous adsorption-induced deformation in microporous materials. The set-up couples a home-built manometric apparatus for gas adsorption measurements and a digital image correlation set-up for full-field displacement measurements.

Figure 1 shows a sketch of the experimental set-up. It is composed of:

- a manometric set-up for gas adsorption measurements:

- a dosing volume $\left(V_{D}\right)$ composed of a dosing cell and a connecting network. The dosing volume is $\left(V_{D} \pm \Delta V_{D}\right)=(95.95 \pm 0.09) \mathrm{ml}$, with a relative error of $\frac{\Delta V_{D}}{V_{D}}=0.09 \%$,

- a measuring volume $\left(V_{M}\right)$ composed of a measuring cell where the sample takes place on a sapphire window. The volume cell is $\left(V_{M}^{0} \pm\right.$ $\left.\Delta V_{M}^{0}\right)=(188.8 \pm 0.3) \mathrm{ml}$ with a relative error of $0.2 \%$,

- a digital manometer (Wiika, measuring range: [0, 250] bar, precision: \pm 0.005 bar $)$,

- an electrical heat regulator (Horst $\mathrm{GmbH}$ HT31) coupled with a PT100 temperature probe,
- two in situ thermocouples $I E C$, type $\mathrm{K},(R S$ thermocouple, precision: $\pm 0.1 \mathrm{~K}$ ) ;

- a digital image correlation set-up for full-field measurements:

- a digital camera (PixeLINK, PL-B781U),

- an optical lens (Edmundoptics, focal length : $25 \mathrm{~mm}$ ),

- a standard LED lighting unit,

- a computer.

\section{B. Gas adsorption measurements}

Excess adsorption isotherms are built step by step from gas adsorption measurements performed using an homebuilt manometric set-up. The manometric technique has been widely used by the community for gas adsorption measurements and different studies may be found in the literature (see e.g. Rouquerol et $a .^{27}$, Battistutta et $a l .{ }^{18}$, Badalyan et $\left.a l .{ }^{28}\right)$. The principle of the technique consists in balancing the gas quantities before and after adsorption thanks to temperature and pressure measurements at the equilibrium.

Carrying out an adsorption isotherm measurement at a given temperature requires different steps:

1. A porous sample, of a known mass $m$, is introduced in the measuring cell.

2. The porous sample is purified under given vacuum and heating conditions (typically $24 \mathrm{~h}$ at $343.15 \mathrm{~K}$ ).

3. An accurate estimation of the measuring volume $V_{M}$ is performed using a non adsorbing gas (typically helium is chosen).

4. The gas adsorption isotherm is finally built step by step by estimating the exceeding adsorbate moles of gas for incremental increasing pressure at thermal equilibrium. At each step, an amount of gas is introduced in the dosing volume $V_{D}$. After equilibrium, pressure and temperature in $V_{D}$ are measured. Then, the gas is allowed to fill the whole system $V_{D}+V_{M}$ and a part of it is adsorbed on the adsorbent sample and a part of it remains nonadsorbed. When the new equilibrium is reached, the new pressure and temperature in the whole system $V_{D}+V_{M}$ are measured and the amount of nonadsorbed gas is deduced. The amount of exceeding adsorbed gas is then estimated by difference following Eq. (1).

$$
\begin{aligned}
\mathrm{n}_{\mathrm{i}}^{\mathrm{ex}} & =\mathrm{n}_{\mathrm{i}-1}^{\mathrm{ex}}+\delta \mathrm{n}_{\mathrm{i}}^{\mathrm{ex}}, \\
\delta \mathrm{n}_{\mathrm{i}}^{\mathrm{ex}} & =\frac{\mathrm{V}_{\mathrm{M}}}{M} \rho_{\mathrm{i}-1}^{\mathrm{M}}+\frac{\mathrm{V}_{\mathrm{D}}}{M} \rho_{\mathrm{i}}^{\mathrm{D}}-\frac{\mathrm{V}_{\mathrm{D}}+\mathrm{V}_{\mathrm{M}}}{M} \rho_{\mathrm{i}}^{\mathrm{M}+\mathrm{D}} .
\end{aligned}
$$

In Eq. (1), $\frac{\mathrm{V}_{\mathrm{M}}}{M} \rho_{\mathrm{i}-1}^{\mathrm{M}}$ is the amount of remaining nonadsorbed gas in the measuring volume $V_{M}$ at the 


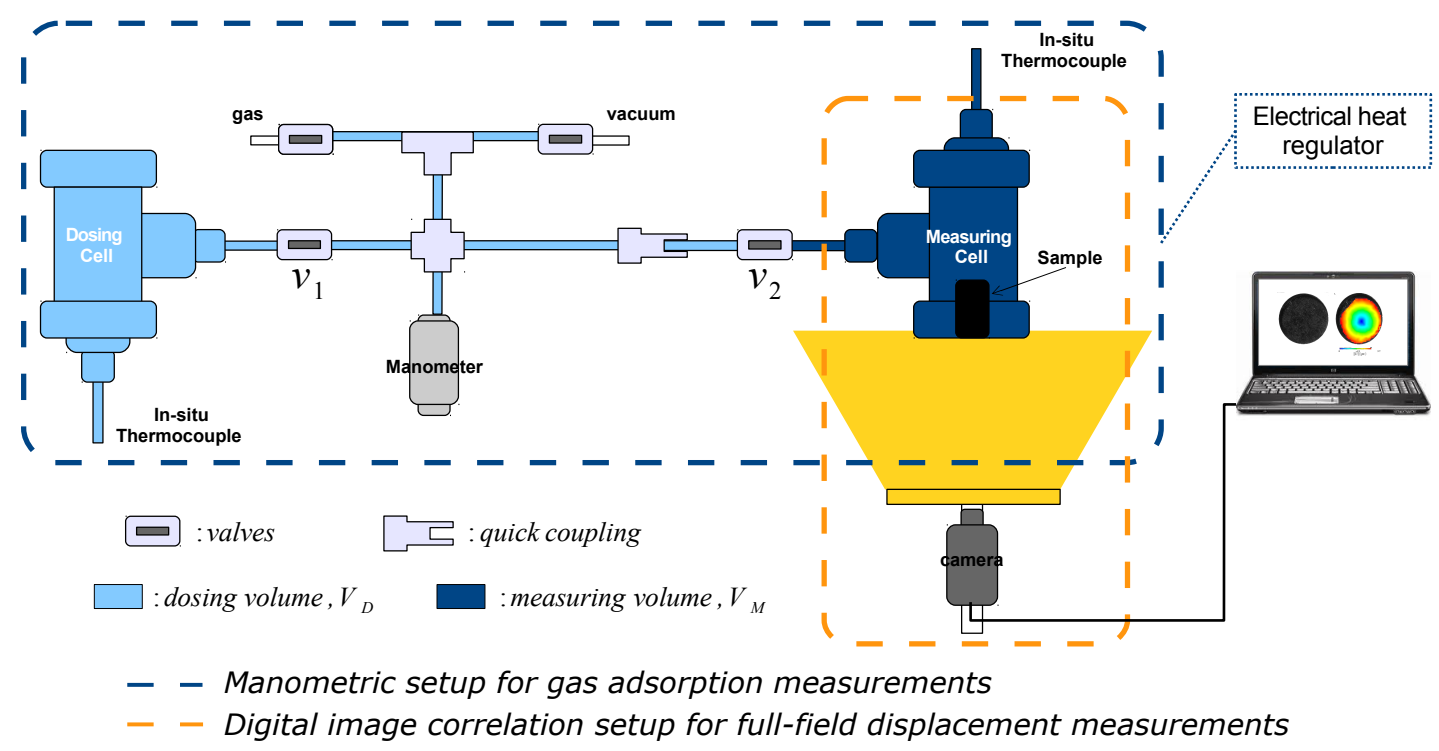

FIG. 1. Sketch of the experimental set-up.

end of step $(i-1), \frac{\mathrm{V}_{\mathrm{D}}}{M} \rho_{\mathrm{i}}^{\mathrm{D}}$ is the amount of gas introduced in the dosing volume $V_{D}$ at the beginning of step $i, \frac{\mathrm{V}_{\mathrm{D}}+\mathrm{V}_{\mathrm{M}}}{M} \rho_{\mathrm{i}}^{\mathrm{M}+\mathrm{D}}$ is the amount of non-adsorbed gas in the whole system at the end of step $i, M$ is the gas molar mass and $\rho$ is the gas density. The subscript represents the pressure step and the superscript represents the volume from which the gas density is estimated through an equation of state for given pressure and temperature. Typically, the equations developed by Span and Wagner ${ }^{29}$, Setzmann and Wagner ${ }^{30}$ and Arp and McCarty ${ }^{31}$ are used to estimate respectively the densities of $\mathrm{CO}_{2}$, $\mathrm{CH}_{4}$ and $\mathrm{He}$.

Since the excess adsorption isotherm is built in an incremental way through Eq. (1), the relative errors accumulate step by step.

Typically, for one excess adsorption amount, the measurement uncertainty is given by Eq. (2).

$$
\begin{aligned}
\Delta \mathrm{n}_{\mathrm{i}}^{\mathrm{ex}} & =\Delta \mathrm{n}_{\mathrm{i}-1}^{\mathrm{ex}}+\left|\rho_{\mathrm{i}-1}^{\mathrm{M}}-\rho_{\mathrm{i}}^{\mathrm{M}+\mathrm{D}}\right| \frac{\Delta \mathrm{V}_{\mathrm{M}}}{M}+\left|\rho_{\mathrm{i}}^{\mathrm{D}}-\rho_{\mathrm{i}}^{\mathrm{M}+\mathrm{D}}\right| \frac{\Delta \mathrm{V}_{\mathrm{D}}}{M} \\
& +\left(\Delta \rho_{\mathrm{i}-1}^{\mathrm{M}}+\Delta \rho_{\mathrm{i}}^{\mathrm{M}}+\mathrm{D}\right) \frac{\mathrm{V}_{\mathrm{M}}}{M}+\left(\Delta \rho_{\mathrm{i}}^{\mathrm{D}}+\Delta \rho_{\mathrm{i}}^{\mathrm{M}+\mathrm{D}}\right) \frac{\mathrm{V}_{\mathrm{D}}}{M} .
\end{aligned}
$$

In Eq. (2), $\Delta \alpha$ is the measurement uncertainty of the quantity $\alpha$.

The manometric part of the device has been validated by comparing the excess adsorption quantities measured on an Ecosorb activated carbon with the ones obtained with a reference gravimetric technique ${ }^{32}$. Figure 2 shows the comparison in term of excess adsorption isotherms $(T=303.15 \mathrm{~K})$ obtained for pure $\mathrm{CH}_{4}(P \in[0-130]$ bar $)$ and pure $\mathrm{CO}_{2}(P \in[0-60]$ bar $)$. A good agreement is clearly observed between the two set of data which validates the manometric technique for adsorption measurements.

Note that different test have been performed to ensure that the temperature is properly stabilised during

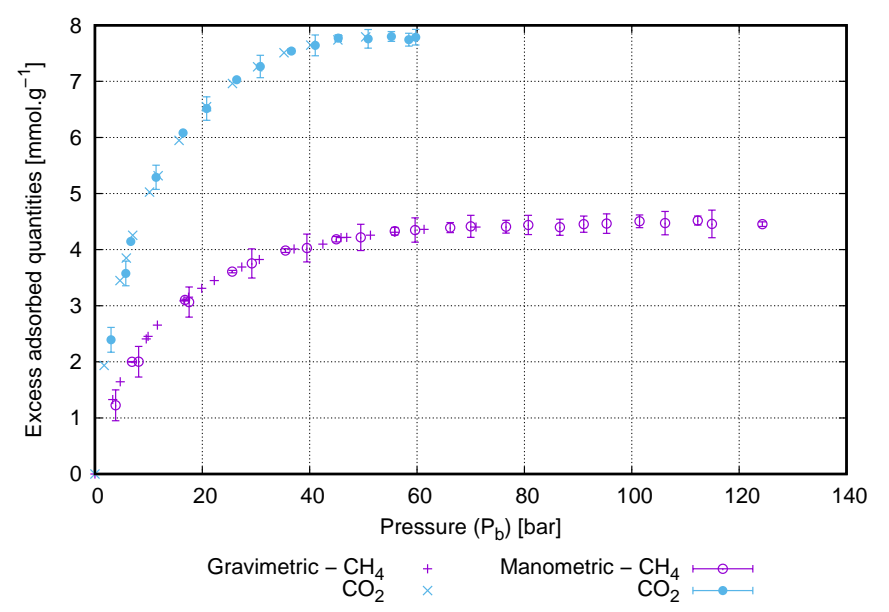

FIG. 2. Comparison of the excess adsorption isotherms measured by the manometric technique (developed in this study) and a reference gravimetric technique (Khaddour et al. ${ }^{32}$ ) for an Ecosorb activated carbon saturated with pure $\mathrm{CH}_{4}$ and pure $\mathrm{CO}_{2}$ at $303.15 \mathrm{~K}$.

the whole measurement duration. A typical temperature shift of $0.1 \mathrm{~K}$ is observed after 12 hours (which corresponds to the thermocouple sensor uncertainty) and the typical duration of a full adsorption isotherm measurement is 6 hours for the material tested here.

\section{Swelling measurement by digital image correlation}

Swelling strain is estimated by full-field displacement measurements performed by digital image correlation (DIC) using Icasoft software ${ }^{33}$. The general framework of the digital image correlation (DIC) algorithm used in this paper is based on the formulation presented by Grégoire 
et $a l .{ }^{34}$. The general principle is briefly recalled in Appendix A. Details may be found in Grégoire et al. ${ }^{34}$.

After purification, a reference image of the surface sample is acquired. At each pressure step, a deformed image is acquired. The two digital images corresponding to the reference and the deformed state are described by a discrete function representing the grey level of each pixel (Eq. A1). The optimal displacement field determination consists in the minimization of a cross-correlation coefficient on a set of image pixels (Eq. A2). The use of a cross-correlation allows to correct a possible difference in brightness between the two images ${ }^{34}$. Thanks to this technique, the full-field displacement is estimated with a typical resolution of $1 / 100$ of a pixel ${ }^{33}$.

Fig. 3 presents a typical result of the full-field displacement estimation preformed by the DIC technique for an activated carbon saturated with pure $\mathrm{CO}_{2}$ at $P_{b}=50.8$ bar. Fig. 3.a, 3.b and 3.c present respectively the reference image and the full-field displacements in the horizontal and vertical directions. A typical adsorptioninduced swelling displacement field is obtained.

From the DIC estimation of the displacement field $\left(\underline{u}=U_{x} \underline{e}_{x}+U_{y} \underline{e}_{y}\right)$, the deformation field is calculated based on a continuum mechanics framework with small displacement-gradient assumption $\left(\underline{\underline{\varepsilon}}=\frac{1}{2}(\underline{\underline{\nabla}}(\underline{u})+\underline{\underline{\nabla}}(\underline{u}))\right)$ as well as the volumetric swelling strain $\left(\varepsilon_{v}=\operatorname{tr}(\underline{\underline{\varepsilon}})\right.$, where $\operatorname{tr}()$ is the trace of the matrix). For an isotropic homogeneous materials, the volumetric swelling strain is directly equal to three times the ortho-radial strain $\left(\varepsilon_{v}=\right.$ $\left.3 \times \varepsilon_{\theta \theta}\right)$. See Appendix B for details on the volumetric swelling strain estimation. For an anisotropic, heterogeneous or cracked material, the volumetric swelling strain is not the measurable quantity of interest and the DICbased method provides the full displacement field on the surface of the material from which the local deformation can be estimated. Figure 4 presents a typical result of the full-field ortho-radial strain estimation for an isotropic and homogeneous activated carbon saturated with pure $\mathrm{CO}_{2}$ at $P_{b}=50.8$ bar. A typical adsorption-induced homogeneous swelling strain field is obtained.

\section{APPLICATION TO THE DETERMINATION OF ADSORPTION-INDUCED SWELLING ON ACTIVATED CARBON.}

\section{A. Adsorbent and adsorbates description}

An activated carbon (Chemviron) is used as adsorbent material in this study. The sample is a cylinder and its main characteristics are collected in Table I. The geometrical dimensions have been measured with a caliper, the mass has been measured with a Precisa scale (XT 2220 M-DR), the specific pore surface has been measured with a gas porosimeter (Micromeretics ASAP 2020) according to the BET theory ${ }^{35}$. The specific micropore volume has been estimated according to the IUPAC classification ${ }^{2}$
TABLE I. Main characteristics of the adsorbent material.

\begin{tabular}{lcr}
\hline \hline Property & Unit & Value \\
\hline Height & $(\mathrm{cm})$ & $h=1.922 \pm 0.004$ \\
Diameter & $(\mathrm{cm})$ & $d=2.087 \pm 0.002$ \\
Volume & $(\mathrm{ml})$ & $V_{e c h}=6.57 \pm 0.03$ \\
Mass & $(\mathrm{g})$ & $m=4.137 \pm 0.001$ \\
Specific pore surface & $\left(\mathrm{m}^{2} \cdot \mathrm{g}^{-1}\right)$ & $S_{\mathrm{BET}}=1090 \pm 10$ \\
Specific micropore volume & $\left(\mathrm{cm}^{3} \cdot \mathrm{g}^{-1}\right)$ & $v_{\phi_{\mu}}=0.51$ \\
Total micropore volume & $(\mathrm{ml})$ & $V_{\phi_{\mu}}=2.11$ \\
Microporosity & $(\%)$ & $\phi_{\mu}=\frac{V_{\phi_{\mu}}}{V_{e c h}}=32.1$ \\
\hline \hline
\end{tabular}

(pore diameter down to $2 \mathrm{~nm}$ ) based on a pore size distribution deduced from a low-pressure adsorption isotherm $\left(N_{2}\right.$ at $77 \mathrm{~K}$ from $8.10^{-8}$ to $0.99 P / P_{0}$ in relative pressure range) measured with the same gas porosimeter according to the HK theory ${ }^{36}$.

The adsorbates, $\mathrm{CO}_{2}$ and $\mathrm{CH}_{4}$, as well as the calibrating gas, $\mathrm{He}$, are provided by Linde Gas with a minimum purity of $99.995 \%, 99.995 \%$ and $99.999 \%$ respectively.

\section{B. Equilibration time, adsorption kinetics and deformation kinetics}

Fig. 5 presents a typical results of the kinetics of sorption and deformation for an activated carbon saturated with pure $\mathrm{CO}_{2}$ at $T=303.15 \mathrm{~K}$ for both adsorption (Fig. 5.a) and desorption (Fig. 5.b) for a bulk pressure varying respectively from $P_{b}=0$ bar to $P_{b}=20$ bar and from $P_{b}=20$ bar to $P_{b}=15$ bar. The thermodynamical equilibrium is reached after a time duration, which is identified equal to $15 \mathrm{~min}$. This duration represents the minimum time increment between two constitutive experimental acquisitions for this material.

\section{Simultaneous adsorption and induced deformation measurements}

The main advantage of the proposed method is to provide simultaneous in situ measurements of both adsorption and deformation for the same sample in the exact same conditions.

Fig. 6 presents the results of these simultaneous measurements for an activated carbon filled with pure $\mathrm{CO}_{2}$ and pure $\mathrm{CH}_{4}$ at $T=318.15 \mathrm{~K}$ and $T=303.15 \mathrm{~K}$ respectively. Full-field deformation maps are presented as supplementary material (see section V). Collected experimental data are reported in appendix D.

Fig. 6.a presents the results in term of excess adsorption/desorption isotherms. $\mathrm{CO}_{2}$ and $\mathrm{CH}_{4}$ gas sorption in activated carbon is a reversible phenomenon and no hysteresis is observed between adsorption and desorption paths as previously reported in the literature ${ }^{32}$. Noting that adsorbed quantity amount increases when temperature decreases, Fig. 6.a shows that $\mathrm{CO}_{2}$ is preferentially 

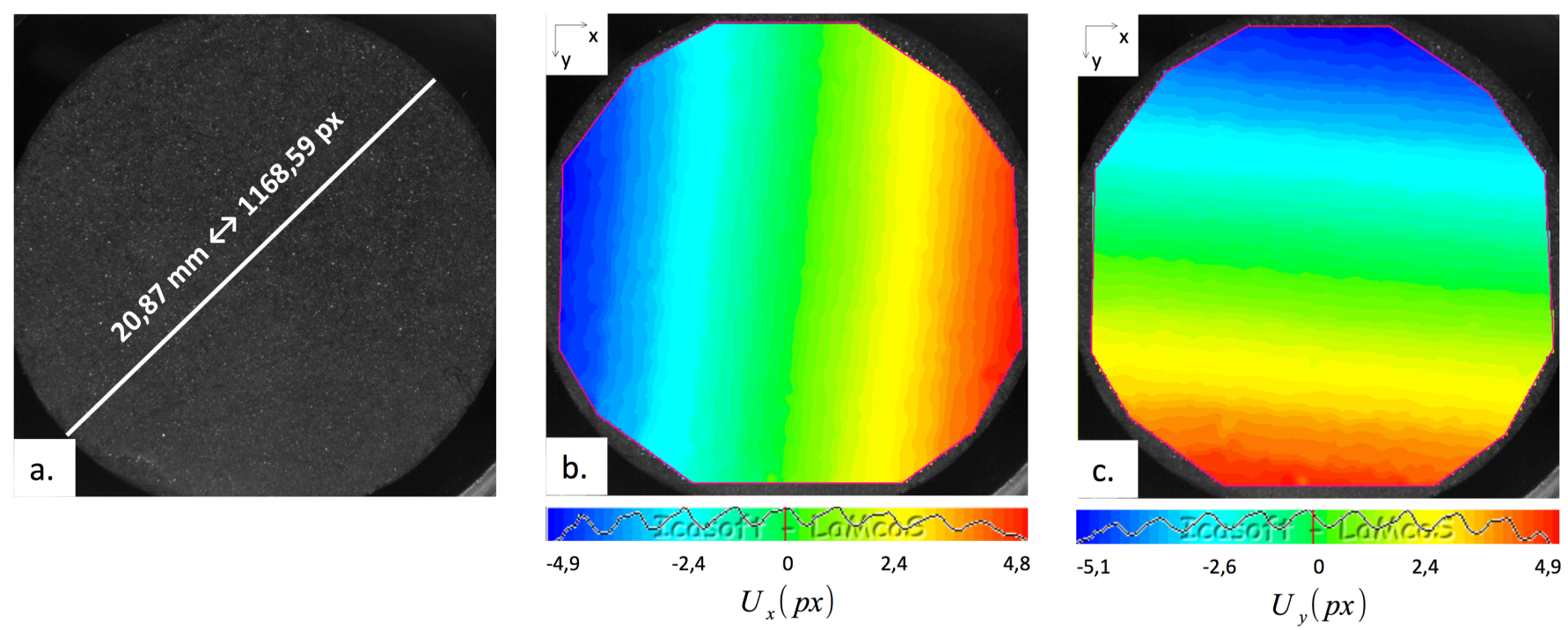

FIG. 3. Typical result of the full-field displacement estimation preformed by the DIC technique for an activated carbon saturated with pure $\mathrm{CO}_{2}\left(T=303.15 \mathrm{~K}, P_{b}=50.8\right.$ bar, pixel size: $\left.17.9 \mu \mathrm{m}\right)$ : (a) reference image; (b) full-field displacement in the horizontal direction; (c) full-field displacement in the vertical direction.

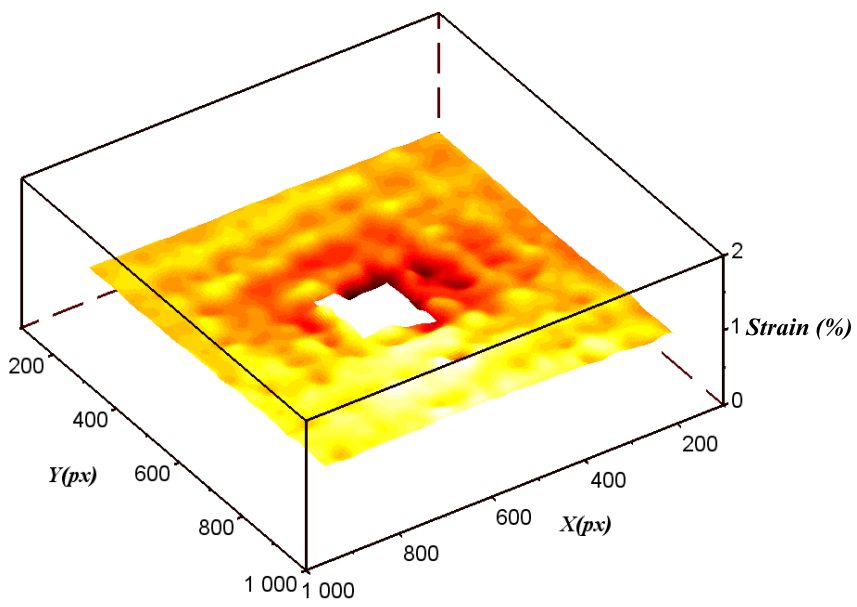

FIG. 4. Typical result of the full-field ortho-radial strain estimation for an activated carbon saturated with pure $\mathrm{CO}_{2}$ $\left(T=303.15 \mathrm{~K}, P_{b}=50.8\right.$ bar, pixel size: $\left.17.9 \mu \mathrm{m}\right)$.

adsorbed in carbon compare to $\mathrm{CH}_{4}$ as previously reported in the literature ${ }^{12,18}$. This is the reason why $\mathrm{CO}_{2}$ injection is used to increase $\mathrm{CH}_{4}$ recovery in Enhanced Coal Bed Methane production.

Fig. 6.b presents the results in term of adsorptioninduced volumetric strain. $\mathrm{CO}_{2}$ and $\mathrm{CH}_{4}$ gas adsorptioninduced deformation is a reversible phenomenon but a small hysteresis is observed between the adsorption and the desorption paths. This hysteresis is not linked to the adsorption-deformation couplings but is due to an elastic compaction of the carbon matrix grains ${ }^{37}$. Cycling effect and material compaction are detailed in appendix C. For a given pressure, $\mathrm{CO}_{2}$ adsorption produces more volumetric deformation than $\mathrm{CH}_{4}$ adsorption, which is the source of the rapid decrease in $\mathrm{CO}_{2}$ injectivity during coal bed methane production enhanced by $\mathrm{CO}_{2}$ injection.

Fig. 7 presents the evolution of the volumetric strain versus the excess adsorbed quantity for both $\mathrm{CO}_{2}$ and $\mathrm{CH}_{4}$ at $T=318.15 \mathrm{~K}$ and $T=303.15 \mathrm{~K}$ respectively. The two evolutions for the two different gases are close together showing that the volumetric swelling is directly linked to the excess adsorbed quantity.

\section{CONCLUDING REMARKS}

A new experimental set-up for the study of adsorptioninduced deformation has been presented. The main advantage of the proposed method is to provide simultaneous in situ measurements of both adsorption and deformation for the same sample in the exact same conditions, which can be directly used for model validation. Gas adsorption measurements are performed using an home-built manometric apparatus and deformation measurements are performed using a digital image correlation set-up. This set-up allows full-field displacement measurements, which may be crucial for heterogeneous, anisotropic or cracked samples. For homogeneous and isotropic samples, homogeneous swelling strain deformation fields are observed and the volumetric swelling strain may be deduced. For an anisotropic, heterogeneous or cracked material, the volumetric swelling strain is not the measurable quantity of interest but the DIC-based method still provides the full displacement field on the surface of the material from which the local deformation can be estimated.

The novel apparatus and the experimental method have been fully detailed and used to characterise in situ adsorption-induced deformation on a nanoporous acti- 

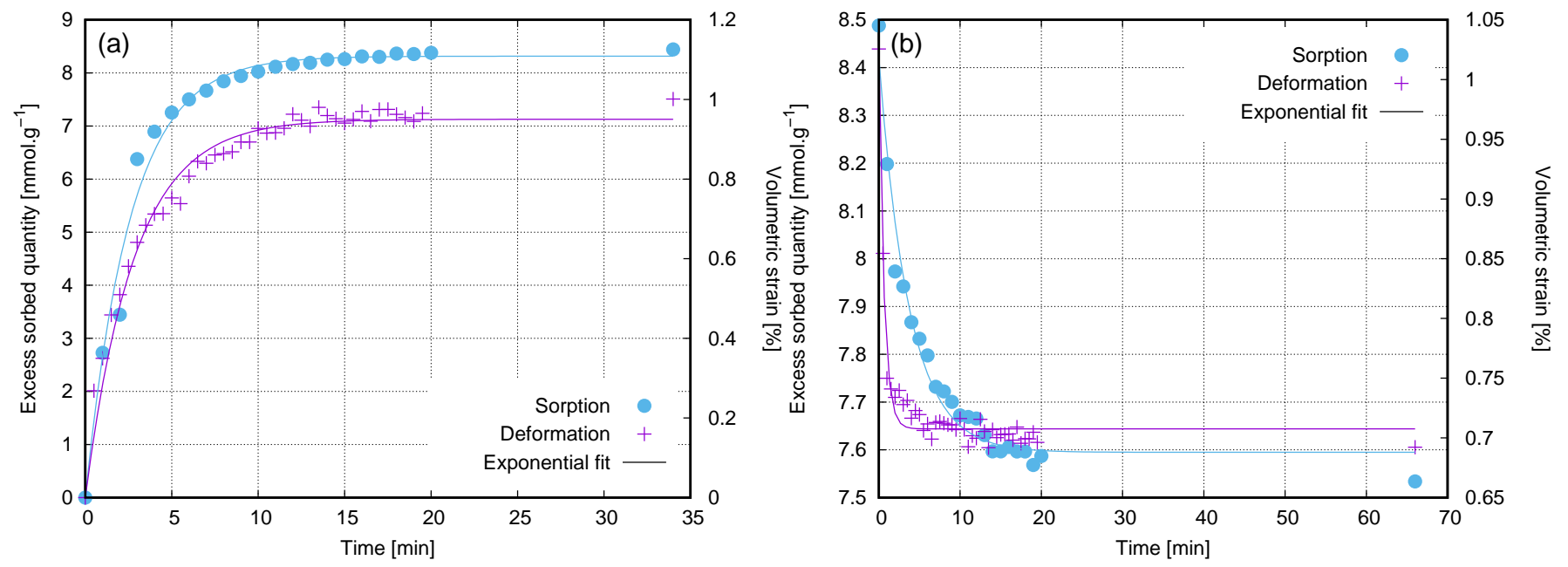

FIG. 5. Typical kinetics of sorption and deformation for an activated carbon saturated with pure $\mathrm{CO}_{2}$ at $T=303.15 \mathrm{~K}$ : (a) adsorption from $P_{b}=0$ bar to $P_{b}=20$ bar; (b) desorption from $P_{b}=20$ bar to $P_{b}=15$ bar.
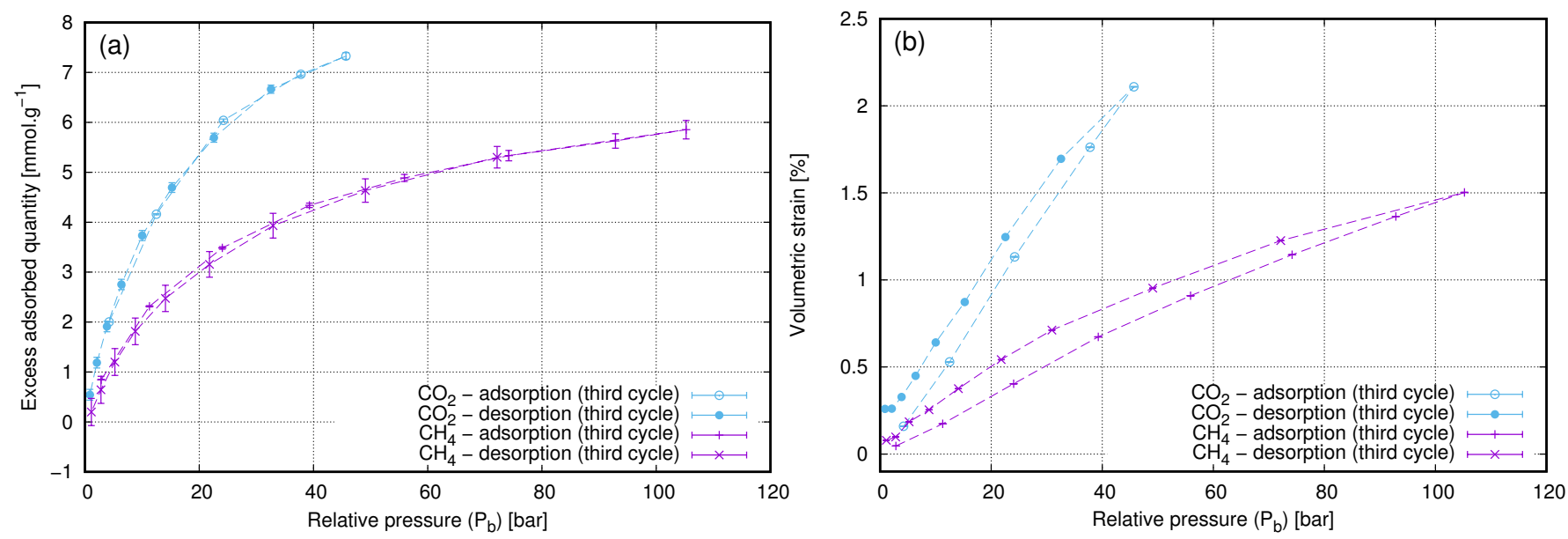

FIG. 6. Simultaneous adsorption and induced swelling measurements for an activated carbon filled with pure $\mathrm{CO}_{2}$ and pure $\mathrm{CH}_{4}$ at $T=318.15 \mathrm{~K}$ and $T=303.15 \mathrm{~K}$ respectively: (a) excess adsorption isotherm; (b) volumetric induced swelling.

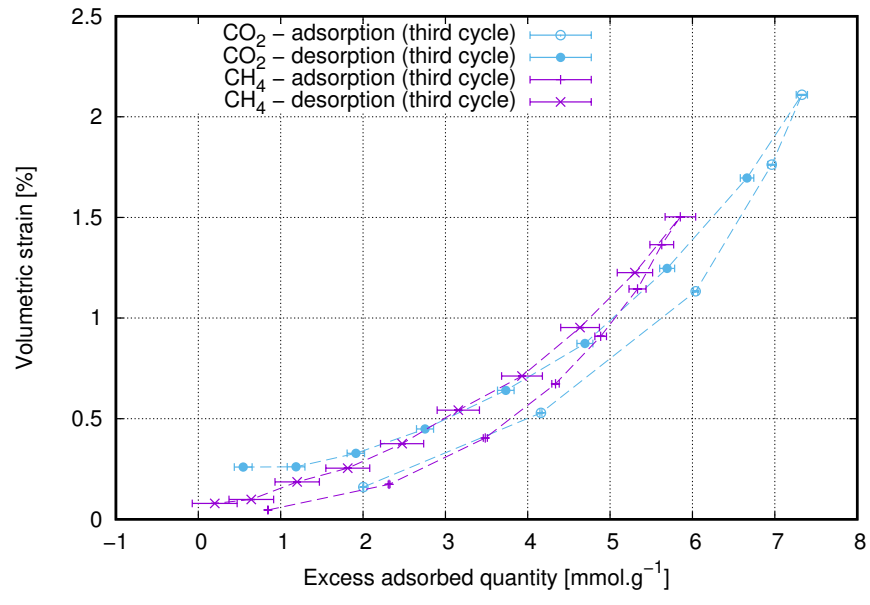

FIG. 7. Swelling versus the excess amount of adsorbed gas $\left(\mathrm{CO}_{2}\right.$ and $\left.\mathrm{CH}_{4}\right)$. vated carbon saturated with pure methane and carbon dioxyde. For a given pressure, $\mathrm{CO}_{2}$ is preferentially adsorbed in this activated carbon compare to $\mathrm{CH}_{4}$ and $\mathrm{CO}_{2}$ adsorption produces more volumetric deformation than $\mathrm{CH}_{4}$ adsorption. However, the simultaneous measurements of both adsorption and strain show that for a given amount of excess adsorbed quantity, a similar induced deformation is observed for $\mathrm{CH}_{4}$ and $\mathrm{CO}_{2}$ showing that the macroscopic swelling is intrinsically linked to the amount of excess adsorbed quantities within the nanopores.

\section{SUPPLEMENTARY MATERIAL}

See supplemental material at [URL will be inserted by AIP] for the full-field deformation maps used to estimated the volumetric swelling evolution presented in Figure 6 based on the procedure presented in appendix B. 


\section{ACKNOWLEDGMENTS}

Financial supports from the Région Aquitaine through the grant CEPAGE (20121105002), from the Conseil Départemental 64 through the grant CEPAGE2 (2015_0768), from the Insitut Carnot ISIFoR and from the Université de Pau et des Pays de l'Adour through the grant Bonus Qualité Recherche are gratefully acknowledged. We also gratefully acknowledge Pr. Gilles Pijaudier-Cabot for him advices and our different discussions.

\section{Appendix A: General framework for digital image correlation}

The general framework of the digital image correlation (DIC) algorithm used in this paper is based on the formulation presented by Grégoire et al. ${ }^{34}$. Here it is now applied for adsorption-induced deformation measurements. The principle of DIC was advanced in the context of experimental mechanics by Sutton et al. ${ }^{38,39}$. Two digital images corresponding to a reference and a deformed state are described by discrete functions representing the grey level of each pixel and related by:

$$
f^{*}\left(x^{*}\right)=f(x+d(x))
$$

where $f$ and $f^{*}$ are the discrete functions of the reference and the deformed state respectively, and $d(x)$ is the displacement field vector (Fig. 8).

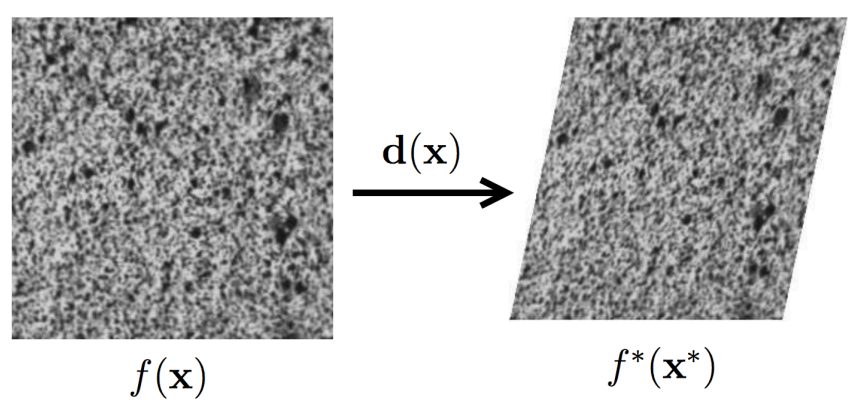

FIG. 8. Reference and deformed images (Grégoire et al. ${ }^{34}$ )

The optimal displacement field determination consists of the minimization of a cross-correlation coefficient on a set of initial image pixels, called a subset:

$$
C=1-\frac{\int_{\Delta M} f(x) f(x+d(x)) d x}{\sqrt{\int_{\Delta M} f^{2}(x) d x \int_{\Delta M} f^{2}(x+d(x)) d x}}
$$

where $\Delta M$ is the surface of the subset in the reference image (see Fig. 9).

The displacement field is typically decomposed on an appropriate functional basis on a subset:

$$
\underline{d}(P)=\sum_{j} n_{j}(P) \underline{u_{j}}
$$

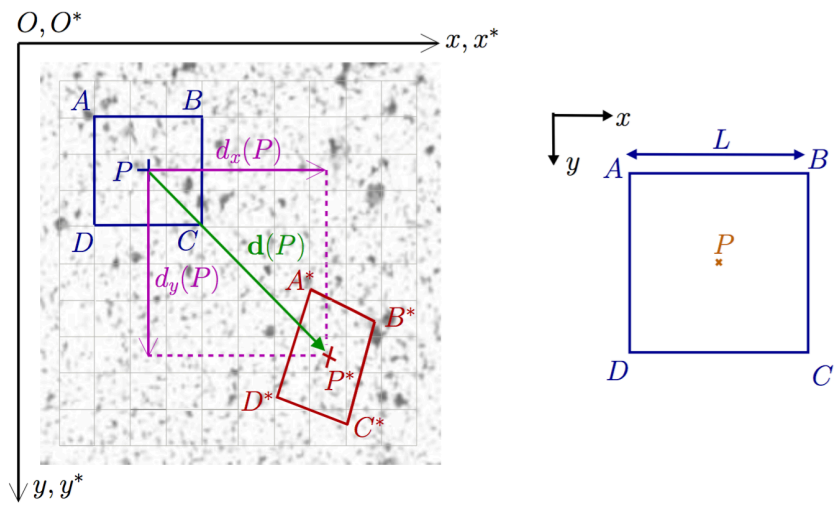

FIG. 9. Initial subset and deformed subset (Grégoire et al. ${ }^{34}$ )

where $\underline{u}_{j}$ are the unknown displacement vectors, $P$ is a point of the subset, $\underline{d}(P)$ is its displacement vector given by the minimization of Eq. (A2) and $n_{j}$ are interpolating functions to be chosen.

According to the numbers of unknowns introduced in the decomposition, Eq. (A3) is written as many times as needed to have a problem well-posed. Finally, the problem consists of inverting a matrix given by:

$$
D=[M] U
$$

where $D$ is the vector of the optimal displacement obtained by the minimization of Eq. (A3), $[M]$ is the matrix of the functional basis and $U$ is the vector of the unknown displacements.

Typically, a bilinear continuous displacement field decomposition $\left(\left\{n_{j}\right\}=\{x, y, x y, 1\}\right)$ and a cubic spline interpolation are used as in Touchal Mguil ${ }^{33}$. Figure 9 shows a subset before $(A B C D$ centered on $P)$ and after $\left(A^{*} B^{*} C^{*} D^{*}\right.$ centered on $\left.P^{*}\right)$ deformation on the same coordinate system. The displacement field is estimated on each point by means of:

$$
\left\{\begin{array}{l}
d_{x}(x, y)=u_{1} \tilde{x}+u_{2} \tilde{y}+u_{3} \tilde{x} \tilde{y}+u_{4} \\
d_{y}(x, y)=u_{5} \tilde{x}+u_{6} \tilde{y}+u_{7} \tilde{x} \tilde{y}+u_{8}
\end{array}\right.
$$

where $\tilde{x}=\frac{x-x_{A}}{L}$ and $\tilde{y}=\frac{y-y_{A}}{L}$ are the homogeneous coordinates and $L$ is the subset length. There are eight unknown $u_{j}$ so Eq. (A5) are written at each point $A$, $B, C$ and $D$. The solution is obtained by inverting the 8-dimensional matrix $[M]$ in Eq. (A4).

Finally, the algorithm is carried out on each subset of the initial image in order to obtain the full field displacement $\underline{u}(x, y)=\left(\begin{array}{c}U_{x}(x, y) \\ U_{y}(x, y)\end{array}\right)_{\left(\underline{e}_{x}, \underline{e}_{y}\right)}$ with a resolution of $1 / 100$ of a pixel. 


\section{Appendix B: Full-field deformation estimation and swelling calculation}

\section{Theoretical background}

Traditionally, the deformation field is calculated based on a continuum mechanics framework with small displacement-gradient assumption $\left(\underline{\underline{\varepsilon}}=\frac{1}{2}(\underline{\underline{\nabla}}(\underline{u})+\right.$ $\underline{\underline{t} \nabla}(\underline{u})))$. For adsorption-induced deformation in an isotropic homogeneous medium, we expect a swelling displacement field and cylindrical coordinates $\left(\underline{e}_{r}, \underline{e}_{\theta}, \underline{e}_{z}\right)$ are more appropriate to estimate the volumetric swelling. One gets:

$$
\underline{\underline{\varepsilon}}=\left(\begin{array}{ll}
\varepsilon_{x x} & \varepsilon_{x y} \\
\varepsilon_{x y} & \varepsilon_{y y}
\end{array}\right)_{\left(\underline{e}_{x}, \underline{e}_{y}\right)}=\left(\begin{array}{ll}
\varepsilon_{r r} & \varepsilon_{r \theta} \\
\varepsilon_{r \theta} & \varepsilon_{\theta \theta}
\end{array}\right)_{\left(\underline{e}_{r}, \underline{e}_{\theta}\right)}
$$

where:

$$
\left\{\begin{array}{l}
\varepsilon_{r r}=\varepsilon_{x x} \cos ^{2} \theta+\varepsilon_{y y} \sin ^{2} \theta+2 \varepsilon_{x y} \cos \theta \sin \theta \\
\varepsilon_{r \theta}=\left(\varepsilon_{y y}-\varepsilon_{x x}\right) \sin \theta \cos \theta+\varepsilon_{x y}\left(\cos ^{2} \theta-\sin ^{2} \theta\right) \\
\varepsilon_{\theta \theta}=\varepsilon_{x x} \sin ^{2} \theta+\varepsilon_{y y} \cos ^{2} \theta+2 \varepsilon_{x y} \cos \theta \sin \theta
\end{array}\right.
$$

and:

$$
\varepsilon_{x x}=\frac{\partial U_{x}}{\partial x} ; \varepsilon_{x y}=\frac{1}{2}\left(\frac{\partial U_{x}}{\partial y}+\frac{\partial U_{y}}{\partial x}\right) ; \varepsilon_{y y}=\frac{\partial U_{y}}{\partial y}
$$

For a perfect swelling deformation field in an isotropic homogeneous medium, one may obtain:

$$
\left\{\begin{array}{cl}
U_{r}(r) & \\
U_{\theta}=0 & \\
\varepsilon_{r r} & =\frac{d U_{r}(r)}{d r}=\text { constant } \\
\varepsilon_{\theta \theta} & =\frac{U_{r}(r)}{r}=\text { constant }=\varepsilon_{r r} \\
\varepsilon_{r \theta} & =0 \\
\varepsilon_{z z} & =\varepsilon_{r r}=\varepsilon_{\theta \theta}
\end{array}\right.
$$

Numerical errors may be introduced during the estimation of a radial strain field based on the numerical differentiation of a discrete radial displacement field (Eq. B4). Therefore, the ortho-radial strain field is directly linked to the norm of the displacement field assuming that the ortho-radial displacement field is negligible $\left(\|\underline{u}\|=\sqrt{U_{r}^{2}+U_{\theta}^{2}} \approx U_{r}\right):$

$$
\varepsilon_{\theta \theta}=\frac{U_{r}(r)}{r}=\frac{\|\underline{u}\|}{\sqrt{\left(x-x_{0}\right)^{2}+\left(y-y_{0}\right)^{2}}}
$$

where $\left(x_{0} ; y_{0}\right)$ is the origin of the cylindrical coordinate system.

Therefore the volumetric swelling is given by:

$$
\varepsilon_{v}=\operatorname{tr}(\underline{\underline{\varepsilon}})=3 \times \varepsilon_{\theta \theta}=3 \times \frac{\|\underline{u}\|}{\sqrt{\left(x-x_{0}\right)^{2}+\left(y-y_{0}\right)^{2}}}
$$

\section{Example and validation}

The method proposed for the estimation of the adsorption-induced volumetric swelling is applied on an activated carbon saturated with pure $\mathrm{CO}_{2}$ at $T=$ $303.15 \mathrm{~K}, P_{b}=50.8$ bar. The resulting full-field displacement estimation performed by the DIC technique is presented in Figure 3.a.

In order to estimate the volumetric swelling through Eq. B5, the origin of the cylindrical coordinate system has to be identified. For this purpose, the norm of the displacement field is interpolated by cubic spline using Scilab software (the interpolation area is represented by a red square in Figure 3.a) and the origin is defined as the point $\left(x_{0}=563.5 \mathrm{px} ; y_{0}=577.2 \mathrm{px}\right)$ where the interpolated field reaches its minimum. Figure 10.b presents the ortho-radial strain estimated in the interpolation area by Eq. B5. A typical constant ortho-radial strain field is obtained in all the interpolation area except in the vicinity of the cylindrical coordinate origin point where a peak artefact is observed. Finally, the volumetric strain is estimated by averaging the ortho-radial strain field in the interpolation area where a mask (represented in white in Figure 10.b) is applied in the vicinity of the cylindrical coordinate origin point to minimize the influence of the artefact peak. The mask dimensions are $150 \times 150$ pixels, which represents $5.6 \%$ of the interpolation area. A volumetric swelling of $\varepsilon_{v}=2.766 \pm 0.003 \%$ is obtained.

The validation of the proposed method is performed by comparing the strain field estimated based on classical continuum mechanics (Eq. B2-B3).

Based on continuum mechanics (Eq. B2-B3), one obtains:

$$
\varepsilon_{r r}=0.947 \% \quad ; \quad \varepsilon_{\theta \theta}=0.920 \% \quad ; \quad \varepsilon_{r \theta}=0.003 \%
$$

Therefore, one indeed observes that $\varepsilon_{r r} \approx \varepsilon_{\theta \theta}, \varepsilon_{r \theta} \approx 0$ and $\varepsilon_{v} \approx 3 \times \varepsilon_{\theta \theta}$.

\section{Appendix C: Cycling effect and material compaction}

This appendix and Figure 11 present the influence of three different loading cycles on both adsorption/desorption isotherms and volumetric swelling strain for an active carbon firstly saturated with pure $\mathrm{CH}_{4}$ at $T=303.15 \mathrm{~K} \pm 0.1 \mathrm{~K}$ and then saturated with pure $\mathrm{CO}_{2}$ at $T=318.15 \mathrm{~K} \pm 0.1 \mathrm{~K}$. The process to produce the active carbon composes three phases: first the carbon is grinded, then it is activated and finally it is compacted to obtain a cylindrical sample. During the first cycle of gas adsorption, there is a competition between a grain compaction shrinkage and the adsorption-induced volumetric swelling and a large hysteresis is observed because of the material compaction. This compaction is mostly irreversible and after the first cycle, the second and the third cycles are superimposed. Note that a small hysteresis remains because a small part of the compaction 

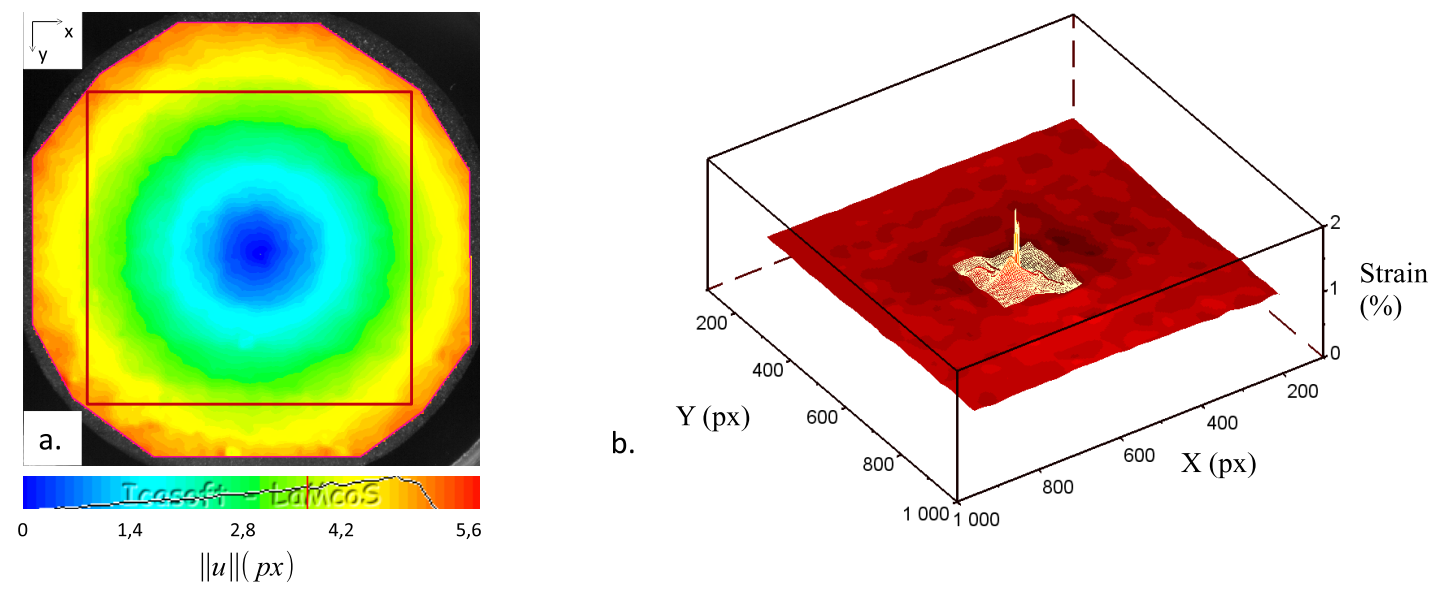

FIG. 10. Adsorption-induced deformation for a activated carbon saturated with pure $\mathrm{CO}_{2}$ at $T=303.15 \mathrm{~K}, P_{b}=50.8$ bar: (a) norm of the displacement field; (b) ortho-radial strain.

phenomenon is elastic. In Figure 6 are presented the data acquired during the third cycle for both $\mathrm{CH}_{4}$ and $\mathrm{CO}_{2}$ gas adsorption.

\section{Appendix D: Collected experimental data}

This appendix collects the experimental data presented in Figure 6.

TABLE II. Collected experimental data in term of relative bulk pressure $\left(P_{b}\right)$, excess adsorbed quantities $\left(n^{e x}\right)$ and swelling strain $\left(\varepsilon_{v}\right)$ for an activated carbon saturated with pure $\mathrm{CH}_{4}$ at $T=303.15 \mathrm{~K} \pm 0.1 \mathrm{~K}$.

\begin{tabular}{ccc}
\hline \hline $\begin{array}{c}P_{b} \\
\text { (bar) }\end{array}$ & $\begin{array}{c}n^{e x} \\
\left(\mathrm{mmol} . \mathrm{g}^{-1}\right)\end{array}$ & $\begin{array}{c}\varepsilon_{v} \\
(\%)\end{array}$ \\
\hline $2.850 \pm 0.005$ & $0.846 \pm 0.003$ & $0.046 \pm 0.006$ \\
$11.280 \pm 0.005$ & $2.316 \pm 0.011$ & $0.174 \pm 0.022$ \\
$24.045 \pm 0.005$ & $3.485 \pm 0.025$ & $0.404 \pm 0.029$ \\
$39.285 \pm 0.005$ & $4.338 \pm 0.045$ & $0.673 \pm 0.063$ \\
$55.915 \pm 0.005$ & $4.886 \pm 0.071$ & $0.909 \pm 0.083$ \\
$74.190 \pm 0.005$ & $5.333 \pm 0.104$ & $1.145 \pm 0.073$ \\
$92.870 \pm 0.005$ & $5.627 \pm 0.144$ & $1.365 \pm 0.036$ \\
$105.230 \pm 0.005$ & $5.853 \pm 0.185$ & $1.503 \pm 0.064$ \\
$72.140 \pm 0.005$ & $5.301 \pm 0.215$ & $1.226 \pm 0.077$ \\
$49.090 \pm 0.005$ & $4.635 \pm 0.235$ & $0.953 \pm 0.089$ \\
$32.930 \pm 0.005$ & $3.931 \pm 0.248$ & $0.712 \pm 0.100$ \\
$21.810 \pm 0.005$ & $3.156 \pm 0.257$ & $0.542 \pm 0.094$ \\
$14.090 \pm 0.005$ & $2.474 \pm 0.263$ & $0.376 \pm 0.074$ \\
$8.805 \pm 0.005$ & $1.815 \pm 0.267$ & $0.254 \pm 0.056$ \\
$5.230 \pm 0.005$ & $1.201 \pm 0.269$ & $0.185 \pm 0.045$ \\
$2.795 \pm 0.005$ & $0.643 \pm 0.271$ & $0.098 \pm 0.026$ \\
$1.115 \pm 0.005$ & $0.200 \pm 0.272$ & $0.079 \pm 0.016$ \\
\hline \hline
\end{tabular}

TABLE III. Collected experimental data in term of relative bulk pressure $\left(P_{b}\right)$, excess adsorbed quantities $\left(n^{e x}\right)$ and swelling strain $\left(\varepsilon_{v}\right)$ for an activated carbon saturated with pure $\mathrm{CO}_{2}$ at $T=318.15 \mathrm{~K} \pm 0.1 \mathrm{~K}$.

\begin{tabular}{ccc}
\hline \hline $\begin{array}{c}P_{b} \\
\text { (bar) }\end{array}$ & $\begin{array}{c}n^{e x} \pm \Delta n^{e x} \\
(\mathrm{mmol.g})\end{array}$ & $\begin{array}{c}\varepsilon_{v} \pm \Delta \varepsilon_{v} \\
(\%)\end{array}$ \\
\hline $4.230 \pm 0.005$ & $2.004 \pm 0.004$ & $0.160 \pm 0.111$ \\
$12.505 \pm 0.005$ & $4.160 \pm 0.013$ & $0.529 \pm 0.088$ \\
$24.230 \pm 0.005$ & $6.039 \pm 0.027$ & $1.133 \pm 0.273$ \\
$37.795 \pm 0.005$ & $6.962 \pm 0.047$ & $1.762 \pm 0.168$ \\
$45.685 \pm 0.005$ & $7.328 \pm 0.068$ & $2.110 \pm 0.176$ \\
$32.570 \pm 0.005$ & $6.662 \pm 0.082$ & $1.696 \pm 0.147$ \\
$22.575 \pm 0.005$ & $5.692 \pm 0.091$ & $1.246 \pm 0.241$ \\
$15.235 \pm 0.005$ & $4.694 \pm 0.097$ & $0.873 \pm 0.224$ \\
$10.005 \pm 0.005$ & $3.734 \pm 0.101$ & $0.641 \pm 0.134$ \\
$6.385 \pm 0.005$ & $2.753 \pm 0.104$ & $0.449 \pm 0.112$ \\
$3.855 \pm 0.005$ & $1.913 \pm 0.106$ & $0.327 \pm 0.117$ \\
$2.095 \pm 0.005$ & $1.187 \pm 0.107$ & $0.261 \pm 0.044$ \\
$0.875 \pm 0.005$ & $0.545 \pm 0.108$ & $0.259 \pm 0.039$ \\
\hline \hline
\end{tabular}

\section{BIBLIOGRAPHY}

${ }^{1}$ K. Sing, D. Everett, R. Haul, L. Moscou, R. Pierotti, J. Rouquerol, and T. Siemieniewska, Pure and Applied Chemistry 57, 603 (1985).

${ }^{2}$ M. Thommes, K. Kaneko, A. V. Neimark, J. P. Olivier, F. Rodriguez-Reinoso, J. Rouquerol, and K. S. W. Sing, Pure and Applied Chemistry 87, 1051 (2015).

${ }^{3}$ M. A. Biot, Journal of Applied Physics 12, 155 (1941).

${ }^{4}$ O. Coussy, Poromechanics (John Wiley \& Sons, Ltd., 2004).

${ }^{5} \mathrm{~J}$. W. Larsen, International Journal of Coal Geology 57, 63 (2004).

${ }^{6}$ Z. Pan and L. Connell, International Journal of Coal Geology 69, 243 (2007).

${ }^{7}$ J. R. Levine, Geological Society, London, Special Publications 109, 197 (1996).

${ }^{8}$ M. Thommes and K. a. Cychosz, Adsorption 20, 233 (2014).

${ }^{9}$ F. T. Meehan, Proceedings of the Royal Society A: Mathematical, Physical and Engineering Sciences 115, 199 (1927). 

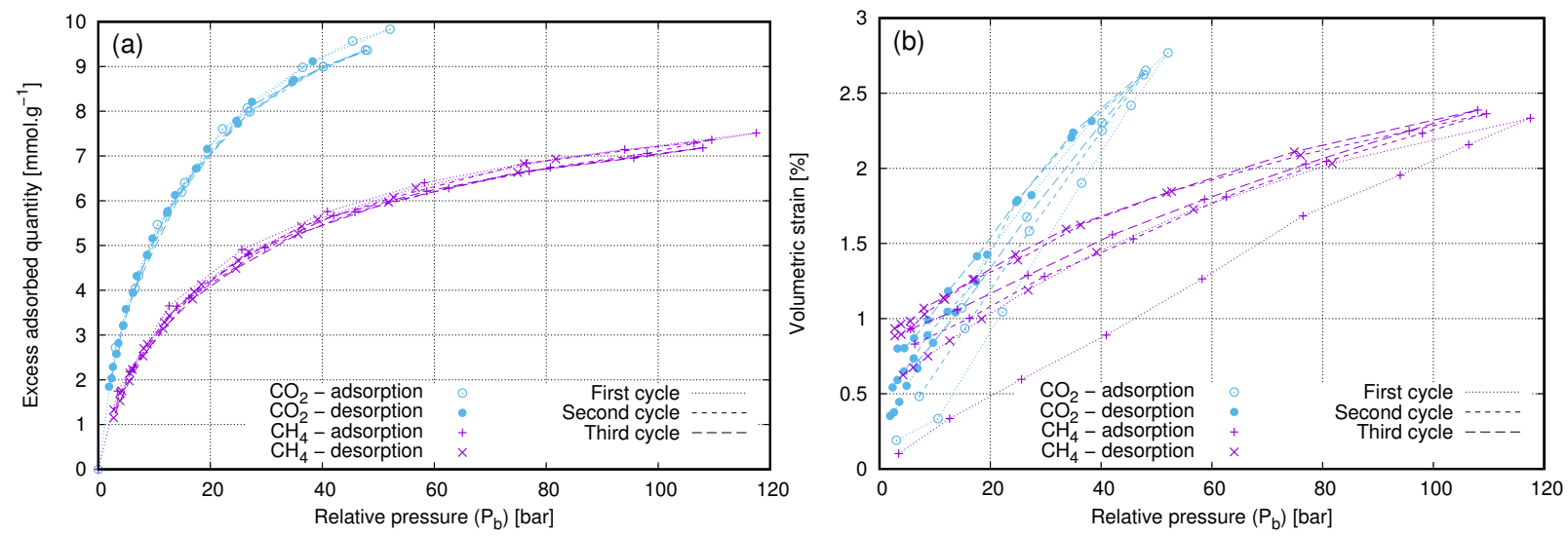

FIG. 11. Simultaneous adsorption and induced swelling measurements (three cycles) for an activated carbon filled with pure $\mathrm{CO}_{2}$ and pure $\mathrm{CH}_{4}$ at $T=318.15 \mathrm{~K}$ and $T=303.15 \mathrm{~K}$ respectively: (a) excess adsorption isotherm; (b) volumetric induced swelling.

${ }^{10}$ H. Briggs and R. P. Sinha, Proceedings of the Royal Society of Edinburgh 53, 48 (1933).

${ }^{11}$ S. Day, R. Fry, and R. Sakurovs, International Journal of Coal Geology 74, 41 (2008).

${ }^{12}$ S. Ottiger, R. Pini, G. Storti, and M. Mazzotti, Adsorption 14, 539 (2008).

${ }^{13}$ R. Pini, S. Ottiger, L. Burlini, G. Storti, and M. Mazzotti, Journal of Geophysical Research: Solid Earth (1978-2012) 114 (2009).

${ }^{14} \mathrm{~S}$. Hol and C. J. Spiers, Journal of the Mechanics and Physics of Solids 60, 1862 (2012).

${ }^{15}$ D. Espinoza, M. Vandamme, J.-M. Pereira, P. Dangla, and S. Vidal-Gilbert, International Journal of Coal Geology 134, 80 (2014).

${ }^{16}$ E. P. Robertson and R. L. Christiansen, in 4th Annual DOE/NETL Conference on Carbon Capture and Sequestration (2005) pp. 1-16.

${ }^{17}$ S. Harpalani and R. A. Schraufnagel, in SPE Annual Technical Conference and Exhibition (Society of Petroleum Engineers, 1990) pp. 171-179.

${ }^{18}$ E. Battistutta, P. Van Hemert, M. Lutynski, H. Bruining, and K.-H. Wolf, International Journal of Coal Geology 84, 39 (2010).

${ }^{19}$ G. Chen, J. Yang, and Z. Liu, Energy \& Fuels 26, 4583 (2012).

${ }^{20} \mathrm{M}$. Vandamme, L. Brochard, B. Lecampion, and O. Coussy, Journal of the Mechanics and Physics of Solids 58, 1489 (2010).

${ }^{21}$ L. Brochard, M. Vandamme, R. J. Pellenq, and T. Fen-chong, Langmuir 28 (2012).

${ }^{22}$ L. Brochard, M. Vandamme, and R. J. Pellenq, Journal of the Mechanics and Physics of Solids 60, 606 (2012).

${ }^{23}$ H. Hoang and G. Galliero, Physical Review E 91, 1 (2015).

${ }^{24}$ L. Perrier, G. Pijaudier-Cabot, and D. Grégoire, Continuum Mechanics and Thermodynamics, May2014 (2014).

${ }^{25}$ R. Vermorel and G. Pijaudier-Cabot, European Journal of Mechanics-A/Solids 44, 148 (2014).
${ }^{26}$ L. Perrier, D. Grégoire, F. Plantier, and G. Pijaudier-Cabot, Procedia Materials Science 3, 1263 (2014).

${ }^{27}$ J. Rouquerol, F. Rouquerol, P. Llewellyn, G. Maurin, and K. S. Sing, Adsorption by powders and porous solids: principles, methodology and applications (Academic press, 2013).

${ }^{28} \mathrm{~A}$. Badalyan, P. Pendleton, and $\mathrm{H}$. Wu, Review of scientific instruments 72, 3038 (2001).

${ }^{29}$ R. Span and W. Wagner, J. Phys. Chem. Ref. Data 25, 1509 (1996).

${ }^{30}$ U. Setzmann and W. Wagner, J. Phys. Chem. Ref. Data 20, 1061 (1991).

${ }^{31}$ V. D. Arp and R. D. McCarty, "Thermophysical properties of helium-4 from 0.8 to $1500 \mathrm{k}$ with pressures to $2000 \mathrm{mpa}$," Tech. Rep. (National Inst. of Standards and Technology, Boulder, CO (USA), 1989).

${ }^{32}$ F. Khaddour, A. Knorst-Fouran, F. Plantier, M. M. Piñeiro, B. Mendiboure, and C. Miqueu, Adsorption 20, 649 (2014).

${ }^{33}$ S. Mguil-Touchal, F. Morestin, and M. Brunet, CMEM 97, 45 (1997).

${ }^{34}$ D. Grégoire, H. Maigre, and F. Morestin, European Journal of Computational Mechanics/Revue Européenne de Mécanique Numérique 18, 255 (2009).

${ }^{35} \mathrm{~S}$. Brunauer, P. H. Emmett, and E. Teller, Journal of the American Chemical Society 60, 309 (1938).

${ }^{36} \mathrm{G}$. Horvath and K. Kawazoe, Journal of Chemical Engineering of Japan 16, 470 (1983).

${ }^{37}$ L. Perrier, Coupling between adsorption and deformation in microporous media, Ph.D. thesis, Université Pau \& Pays Adour (2015).

${ }^{38}$ M. Sutton, W. Wolters, W. Peters, W. Ranson, and S. McNeill, Image and vision computing 1, 133 (1983).

${ }^{39}$ M. Sutton, C. Mingqi, W. Peters, Y. Chao, and S. McNeill, Image and Vision Computing 4, 143 (1986). 